\title{
Two Personality Variables and the Cross-cultural Adjustment of Study Abroad Students
}

\author{
J. Kline Harrison \\ Wake Forest University
}

\section{Elizabeth Voelker \\ Wake Forest University}

In its Open Doors 2005 annual report, the Institute of International Education reports that the number of students who study abroad has steadily increased over the past few decades, with a record number of over 190,000 going abroad in 2003/04 ("U.S. Study Abroad," 2005). The programs in which these students participate are no longer seen strictly as a campus extension of academic exercise, but as an overall educational experience that develops holistic life skills in the participants (Berg, 2003). In a survey focused on the personal, academic, and professional lives of study abroad alumni from 1950 to 1999, Dwyer and Peters (2004) found that sojourns abroad have a significant, positive influence on the career path, worldview, and self-confidence of students.

Given the growth and impact of international educational experiences, it is important to assess the effectiveness of study abroad programs and to identify and evaluate the contributing factors to students' success; however, a recent survey of leading U.S. study abroad institutions found that $96 \%$ of questionnaires only assessed students' satisfaction as the single measurement of success (Berg, 2003). In contrast, the literature on international job assignments identifies cross-cultural adjustment as the vital construct underlying the success of expatriate employee experiences (Bhaskar-Shrinivas, Harrison, Shaffer, \& Luk, 2005). Furthermore, personality characteristics are considered among the most important factors affecting the adjustment of expatriate employees, and thus their success (Huang, Chi \& Lawler, 2005; Jassawalla, Truglia, \& Garvey, 2004).

One personality characteristic identified in recent literature on crosscultural adjustment is emotional intelligence (EI). Gabel, Dolan and Cerdin (2005) found EI to play an important role in explaining cross-cultural adjustment and thereby expatriate employee success. Nevertheless, a literature review 
revealed no research on the potential impact of emotional intelligence on the adjustment of study abroad students.

Another personality characteristic, entrepreneurial attitude, is a composite of four constructs that individually have been investigated in previous research on expatriate employee adjustment. These constructs - need for achievement, innovation, personal control and self-confidence (Robinson, Stimpson, Huefner \& Hunt, 1991) — which have been reflected in the adjustment literature as conscientiousness (Shaffer, Harrison, Gregersen, Black \& Ferzandi, 2006), openness to experience (Huang et al., 2005), locus of control (Black, 1990), and self-efficacy (Harrison, Chadwick \& Scales, 1996), respectively. Nevertheless, neither entrepreneurial attitude nor its underlying constructs have been examined previously in the literature on adjustment among study abroad students.

Therefore, this study focuses on the above personality characteristics which are expected to impact the cross-cultural adjustment of students while studying abroad. Based on self-assessments by university students who have studied abroad for a semester, this research examines the impact of both emotional intelligence (EI) and entrepreneurial attitude orientation (EAO) on their adjustment to their host culture.

\section{Cross-Cultural Adjustment}

Cross-cultural adjustment is generally conceptualized as the degree of a person's psychological comfort with a variety of aspects of a host culture (Black, 1988; Nicholson, 1984). This comfort develops as uncertainty is reduced through the learning of behaviors that are appropriate in the new culture and those that are not (Black \& Gregersen, 1991). Hence, a major challenge to expatriate adjustment is overcoming cultural barriers. Expatriates must adapt their attitudes/behaviors to better fit within their host culture and thus, increase their effectiveness (Huang et al., 2005).

According to Black, Mendenhall and Oddou (1991), cross-cultural adjustment is a multidimensional construct rather than a unitary phenomenon. The three dimensions that comprise this construct are: general adjustment to the foreign culture (i.e., living conditions abroad such as food, housing, transportation, and shopping); interaction adjustment with host country nationals (i.e., socializing and speaking with individuals in the host culture), and work adjustment (i.e., adapting to job requirements, organizational culture, work supervision, and performance expectations) (Gabel et al., 2005). In research conducted among students, the third dimension is excluded for obvious reasons (Robie \& Ryan, 1996). 
As stated previously, the literature has identified personality characteristics as important potential factors leading to expatriate adjustment (Jassawalla et al., 2004). According to Huang et al. (2005), if a clear relationship can be found between specific personality characteristics and cross-cultural adjustment, then more effective selection criteria can be developed and greater expatriate successes can be achieved. Two aforementioned characteristics that seem applicable to adjustment in study abroad situations are emotional intelligence and entrepreneurial attitude.

\section{Emotional Intelligence}

Mayer and Salovey (1993) define the personality characteristic of emotional intelligence (EI) as "a type of social intelligence that involves the ability to monitor one's own and others' emotions, to discriminate among them, and to use the information to guide one's thinking and actions" (p.433). Hence, EI relates to a number of non-cognitive skills, abilities, or competencies that impact an individual's ability to deal with environmental demands and pressures (Rahim \& Psenicka, 2002).

Salovey and Mayer (1990) and Mayer and Salovey (1997) conceptualize EI as a composite of four distinct dimensions: self emotional appraisal (the ability to understand one's deep emotions and to express them naturally); others' emotional appraisal (the ability to understand the emotions within other people); use of emotion (the ability to make use of one's emotions in constructive and productive ways); and regulation of emotion (the ability to regulate one's emotion and to rebound from distress). These dimensions of EI play an important role in explaining the cross-cultural adjustment and thus, the corresponding success of expatriates. According to Gabel et al. (2005), EI helps to diminish the cultural differences between the host and home cultures of expatriates, and thereby increases the possibilities for better cross-cultural adjustment.

Given that prior research has advocated the value of training in EI for prospective study abroad students (Ornstein \& Nelson, 2006) and has shown the impact of EI on expatriate adjustment (Gabel et al., 2005), it seems logical to extend this research to determine if EI enables students to better adjust to their host cultures and thus have a more successful sojourn. Therefore, it is hypothesized that:

H1: Study abroad students with high emotional intelligence scores on (a) self emotional appraisal, (b) others' emotional appraisal, (c) use of emotion, and (d) regulation of emotion will demonstrate greater general adjustment 
to the host culture than their counterparts who are lower on these EI dimensions.

H2: Study abroad students with high emotional intelligence scores on (a) self emotional appraisal, (b) others' emotional appraisal, (c) use of emotion, and (d) regulation of emotion will demonstrate greater interaction adjustment to the host culture than their counterparts who are lower on these EI dimensions.

\section{Entrepreneurial Attitude Orientation (EAO)}

Huefner and Hunt (1994) broadly define entrepreneurship as: "recognizing an opportunity and marshalling the resources to take advantage of or act on that opportunity" (p. 61). It seems that entrepreneurial individuals have personal characteristics that give them the propensity to prosper amid change, chaos, and confusion (McCline, Bhat \& Baj, 2000). Based on their review of the literature on both personality and entrepreneurship, Robinson et al. (1991) identified four personality constructs that have been commonly used in research on entrepreneurs: need for achievement, innovation, personal control, and self-confidence. According to Robinson et al. (1991), these four constructs, taken together, constitute a composite personality characteristic identified as "entrepreneurial attitude orientation" or EAO.

Although, no research was found on EAO among expatriate employees or study abroad students, a review of the literature on expatriate employee adjustment revealed a variety of studies on personality attributes that reflect the underlying constructs of EAO. Specifically, need for achievement is reflected in the research on conscientiousness (Shaffer, Harrison, Gregersen, Black \& Ferzandi, 2006), which scholars indicate includes the motivation to achieve (McShane \& Von Glinow, 2005); innovation is aligned with studies on openness to experience (Huang et al., 2005), which describes individuals in terms of their being original, innovative, and willing to take risks (Costa \& McCrae, 1992); personal control is examined in the literature on locus of control (Black, 1990), which is the degree to which individuals feel they have control over their personal lives (McShane \& Von Glinow, 2005); and self-confidence is reflected in the research on self-efficacy (Harrison et al., 1996), which is defined as the level of confidence that individuals have in their ability to accomplish tasks (Bandura, 1986).

Given these underlying constructs impact expatriate employee adjustment, it seems logical that, taken together as EAO, they will have a com- 
parable impact on study abroad students' adjustment to their host culture. Because these students are more likely to be achievement-oriented (Schroth \& McCormack, 2000) and open to experience (Bakalis \& Joiner, 2004) than nonsojourners, and because their self-determination (i.e., self-efficacy and locus of control) has been found to impact their global awareness and appreciation (Harrison, 2006), it follows that they, too, should experience greater cultural adjustment. Therefore, it is hypothesized that:

H3: Study abroad students with a high EAO will demonstrate greater general adjustment to the host culture than their counterparts who have a lower EAO.

H4: Study abroad students with a high EAO will demonstrate great interaction adjustment to the host culture than their counterparts who have a lower EAO.

\section{Method}

\section{Respondents}

This study was conducted among undergraduate sojourners from a small, private university in the southeastern United States. A sample of 456 students was surveyed via e-mail, with 347 receiving a web-based questionnaire after returning from a fall semester abroad and another 109 receiving the same questionnaire towards the end of the spring semester while they were still abroad. Approximately two weeks after the initial mailing was sent, a follow-up e-mail was posted asking nonrespondents for their cooperation in completing the questionnaire. One hundred ninety-one total surveys were ultimately returned for a $42 \%$ representation, which is an average response rate for electronic surveys in the academic sector (Ilieva, Baron, and Healey, 2002).

Regarding the background of respondents, 59 were males and 132 were females. Of these 191 students, 147 completed the survey during the fall semester and 44 completed it during the spring. Twelve percent of the total group were in their sophomore year of study, 85 percent in their junior year, and 3 percent in their senior year. Business majors represented the highest number of respondents within a discipline at 23 percent. Psychology majors followed at 21 percent, with a cross-section of majors comprising the remaining 56 percent. While only 17 percent of the respondents had lived abroad previously, 78 percent had traveled internationally before their study abroad experience. 


\section{Measures}

The questionnaire used in this study consisted of participants' self-assessment on both independent and dependent measures. Specifically, widely recognized standardized instruments with high reliabilities were used to assess the dependent variable of cross-cultural adjustment, as well as the independent variables of emotional intelligence and entrepreneurial attitude orientation.

To measure cross-cultural adjustment, a nine-item measure was drawn from Black and Stephens' (1989) study of expatriate adjustment. The current version was adapted by Robie and Ryan (1996) to fit a school context by rewording or excluding work-related items (see Appendix 1). As expected, the resulting nine nonwork items yielded two subdimensions of general and interaction adjustment, with alpha coefficients of .76 and .88, respectively. All responses were measured on a 5-point Likert scale ranging from "almost no adjustment" to "tremendous adjustment."

To assess respondents' level of emotional intelligence, a psychometrically sound and practical short measure developed by Wong and Law (2002) was used (see Appendix 2). Their research on the measure confirmed its reliability and validity based on analyses of factor structure, internal consistency, convergence, and discriminant and incremental validity. In the present study, responses to the measure were assessed on a 5-point Likert scale ranging from "strongly disagree" to "strongly agree" and yielded an alpha coefficient of .83. Furthermore, consistent with the analyses by Wong and Law (2002), subdimensions of the construct were confirmed by reliability analysis, with alpha coefficients of .80, $.81, .79$, and .87 for self emotional appraisal, others' emotional appraisal, use of emotion, and regulation of emotion, respectively.

To assess entrepreneurial attitude orientation (EAO), an abbreviated version of Robinson et al.'s (1991) scale was used. This measure consisted of 27 items taken from the original scale containing 76 items (see Appendix 3). Because the literature suggests that behavior components of attitude (e.g., behavioral intentions) are better predictors of subsequent overt behavior than affective or cognitive components (Breckler, 1984; Kothandapani, 1971), only items focused on behavioral intentions were included for practicality. Using a 5-point Likert scale ranging from "strongly disagree" to "strongly agree," these items were then rewritten from a business context to a general, nonspecific context per Huefner and Hunt (1994). Comparable to Robinson et al.'s (1991) finding on the behavior component of the EAO, the reliability of the measure was affirmed in the present study with an alpha coefficient of .79. It should be noted, however, that contrary to other studies on the EAO 
(e.g., Robinson et al. [1991] and van Wyk and Boshoff [2004]), subdimensions of achievement, innovation, perception of personal control and perceived self-esteem were not specified through confirmatory factor analysis using the behavioral items only.

In addition to the aforementioned measures, the questionnaire also included items regarding relevant background information. These items addressed gender, year of academic study, college major, and previous experience abroad either as a resident or tourist.

\section{Res u I t s}

\section{Test of Hypotheses}

Hypotheses 1 stated that study abroad students with high emotional intelligence scores on (a) self emotional appraisal, (b) others' emotional appraisal, (c) use of emotion, and (d) regulation of emotion would demonstrate greater general adjustment to the host culture than their counterparts who were lower on these EI dimensions. One-tailed correlational tests indicated a significant, positive correlation between general adjustment and self emotional appraisal $(\mathrm{r}=.33, \mathrm{p}<.01)$, others' emotional appraisal $(\mathrm{r}=.19, \mathrm{p}<.01)$, use of emotion $(\mathrm{r}=.22, \mathrm{p}<.01)$ and regulation of emotion $(\mathrm{r}=.19, \mathrm{p}<.01)$ as shown in Table 1.

Consistent with past research on personality variables and cross-cultural adjustment (e.g., Black, 1990; Harrison et al., 1996), a median split procedure was performed on the personality variables within this study. Respondents with EI above the median on each subdimension were categorized as having high EI and those below the median were categorized as having low EI. One-way ANOVA results generally supported the first hypothesis (see Table 2). Those with high self emotional appraisal $(x=27.21, \mathrm{sd}=4.12)$ were significantly different from those with lower self emotional appraisal $(\mathrm{x}=24.53$, $\mathrm{sd}=4.48)$ on general adjustment $(\mathrm{F}[1,181]=16.56, \mathrm{p}<.01)$; those with high others' emotional appraisal $(\mathrm{x}=26.74$, sd $=4.44)$ were significantly different from those with lower others' emotional appraisal $(\mathrm{x}=25.14$, $\mathrm{sd}=4.23)$ on general adjustment $(\mathrm{F}[1,182]=5.25, \mathrm{p}<.05)$; and those with high use of emotion $(\mathrm{x}=26.72, \mathrm{sd}=4.42)$ were significantly different from those with lower use of emotion $(\mathrm{x}=25.28, \mathrm{sd}=4.32)$ on general adjustment $(\mathrm{F}[1,182]=4.42$, $\mathrm{p}<.05)$. The difference between those with high regulation of emotion $(\mathrm{x}=$ $26.75, \mathrm{sd}=4.56)$ and those with lower regulation of emotion $(\mathrm{x}=25.48$, sd $=4.14)$ only approached significance at the $\mathrm{p}<.10$ level in terms of general adjustment $(\mathrm{F}[1,182]=3.66, \mathrm{p}<.06)$. 


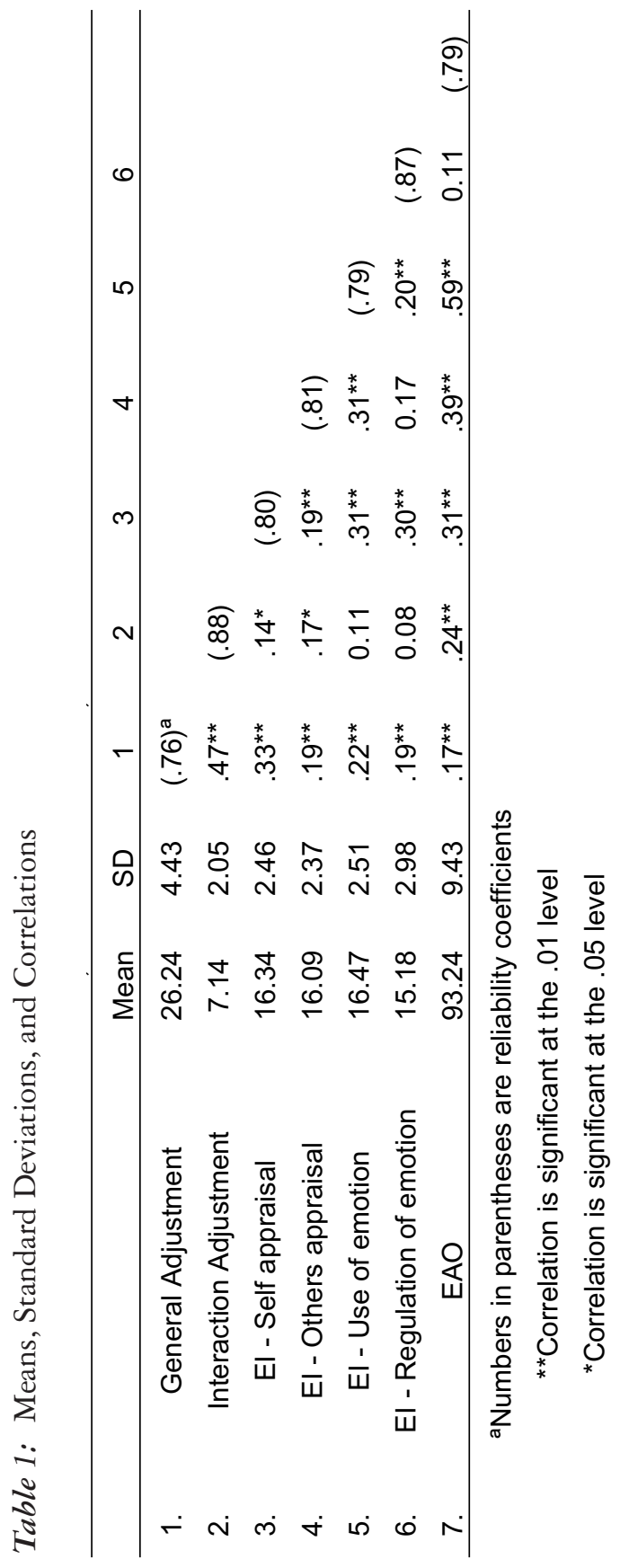


Table 2: Means and Standard Deviations of Median Splits for Emotional Intelligence

\begin{tabular}{|c|c|c|c|}
\hline & $\begin{array}{l}\text { High Self } \\
\text { Emotional } \\
\text { Appraisal } \\
\end{array}$ & $\begin{array}{l}\text { Low Self } \\
\text { Emotional } \\
\text { Appraisal } \\
\end{array}$ & $\mathrm{F}$ \\
\hline General Adjustment M & 27.21 & 24.53 & $16.56^{* *}$ \\
\hline General Adjustment SD & 4.12 & 4.48 & \\
\hline Interaction Adjustment M & 7.30 & 6.85 & 2.10 \\
\hline \multirow[t]{2}{*}{ Interaction Adjustment SD } & 2.08 & 1.99 & \\
\hline & $\begin{array}{l}\text { High Others' } \\
\text { Emotional } \\
\text { Appraisal } \\
\end{array}$ & $\begin{array}{l}\text { Low Others' } \\
\text { Emotional } \\
\text { Appraisal }\end{array}$ & $\mathrm{F}$ \\
\hline General Adjustment M & 26.74 & 25.14 & $5.25^{*}$ \\
\hline General Adjustment SD & 4.44 & 4.23 & \\
\hline Interaction Adjustment M & 7.44 & 6.53 & $8.43^{\star *}$ \\
\hline \multirow[t]{2}{*}{ Interaction Adjustment SD } & 2.06 & 1.92 & \\
\hline & $\begin{array}{l}\text { High Use of } \\
\text { Emotion }\end{array}$ & $\begin{array}{c}\text { Low Use of } \\
\text { Emotion }\end{array}$ & $\mathrm{F}$ \\
\hline General Adjustment M & 27.72 & 25.28 & $4.42^{*}$ \\
\hline General Adjustment SD & 4.42 & 4.32 & \\
\hline Interaction Adjustment M & 7.27 & 6.89 & 1.45 \\
\hline \multirow[t]{2}{*}{ Interaction Adjustment SD } & 2.14 & 1.87 & \\
\hline & $\begin{array}{c}\text { High } \\
\text { Regulation } \\
\text { of Emotion }\end{array}$ & $\begin{array}{l}\text { Low } \\
\text { Regulation of } \\
\text { Emotion }\end{array}$ & $\mathrm{F}$ \\
\hline General Adjustment M & 26.75 & 25.48 & 3.36 \\
\hline General Adjustment SD & 4.56 & 4.14 & \\
\hline Interaction Adjustment M & 7.20 & 7.05 & 0.24 \\
\hline Interaction Adjustment SD & 1.97 & 2.19 & \\
\hline
\end{tabular}

Hypothesis 2 stated that study abroad students with high emotional intelligence scores on (a) self emotional appraisal, (b) others' emotional appraisal, (c) use of emotion, and (d) regulation of emotion would demonstrate greater interaction adjustment to the host culture than their counterparts who are lower on these EI dimensions. One-tailed correlational tests (see Table 1) indicated a significant, positive correlation between interaction adjustment and both self emotional appraisal $(\mathrm{r}=.14, \mathrm{p}<.05)$ and others' emotional appraisal $(\mathrm{r}=.17$, 
$\mathrm{p}<.05)$. Although the correlation between interaction adjustment and the use of emotion approached significance at the .10 level $(\mathrm{r}=.11, \mathrm{p}<.07)$, there was no significant relationship between interaction adjustment and regulation of emotion $(\mathrm{r}=.08, \mathrm{~ns})$.

Again, a median split procedure was performed in which respondents with EI above the median on each subdimension were categorized as having high EI and those below the median were categorized as having low EI. One-way ANOVA results supported only hypothesis 2(b) (see Table 2). Those with high others' emotional appraisal $(\mathrm{x}=7.44$, $\mathrm{sd}=2.06)$ were significantly different from those with lower others' emotional appraisal $(\mathrm{x}=6.53$, sd $=1.92)$ on interaction adjustment $(\mathrm{F}[1,188]=8.43, \mathrm{p}<.01)$.

Hypotheses 3 and 4 stated that, compared to study abroad students with a lower entrepreneurial attitude orientation (EAO), study abroad students with a high EAO would demonstrate greater general adjustment and greater interaction adjustment, respectively. One-tailed correlational tests indicated a significant, positive correlation between $\mathrm{EAO}$ and both general adjustment $(\mathrm{r}=.17$, $\mathrm{p}<.05)$ and interaction adjustment $(\mathrm{r}=.24, \mathrm{p}<.01)$ as shown in Table 1.

Consistent with the procedure for EI, a median split procedure was performed in which respondents with $\mathrm{EAO}$ scores above the median were categorized as having a high EAO and those below the median were categorized as having a low EAO. One-way ANOVA results supported hypothesis 4, but not 3 (see Table 3). Respondents with a high EAO ( $\mathrm{x}=7.47, \mathrm{sd}=2.11)$ were significantly different from those with a lower $\mathrm{EAO}(\mathrm{x}=6.80, \mathrm{sd}=1.95)$ on interaction adjustment $(\mathrm{F}[1,187]=5.21, \mathrm{p}<.05)$; however, respondents with a high $\mathrm{EAO}(\mathrm{x}=26.60$, sd $=4.46)$ were not significantly different from those with a lower $\mathrm{EAO}(\mathrm{x}=25.96$, $\mathrm{sd}=4.38)$ on general adjustment $(\mathrm{F}[1,181]=.98, \mathrm{~ns})$.

Table 3: Means and Standard Deviations of Median Splits for Entrepreneurial Attitude Orientation

\begin{tabular}{lccc} 
& $\begin{array}{c}\text { High } \\
\text { EAO }\end{array}$ & $\begin{array}{c}\text { Low } \\
\text { EAO }\end{array}$ & F \\
\hline General Adjustment M & 26.60 & 25.96 & 0.98 \\
General Adjustment SD & 4.46 & 4.38 & \\
Interaction Adjustment M & 7.47 & 6.80 & $5.21^{*}$ \\
Interaction Adjustment SD & 2.11 & 1.95 & \\
\hline
\end{tabular}

${ }^{*}$ Correlation is significant at the 0.05 level (1-tailed). 


\section{Di s c us i on}

The purpose of this research was to investigate the cross-cultural adjustment of study abroad students and the associated impact of two personality variables — emotional intelligence and entrepreneurial attitude orientation. Results indicated that three subdimensions of EI were significantly related to general adjustment in a host culture, with the fourth subdimension tending to be influential. Individuals with higher self-emotional appraisal, higher others' emotional appraisal, and higher use of emotion exhibited stronger general adjustment than those who scored lower on these dimensions. Similarly, those who were higher on regulation of emotion tended to have stronger general adjustment. It seems that dimensions of EI play an important role in the general adjustment of study abroad students.

With respect to interaction adjustment, the results were not as strong. Only one of the subdimensions of EI was significant. Students with higher others' emotional appraisal exhibited stronger interaction adjustment than their counterparts. It seems that emotional appraisal of others plays the most important role for study abroad students when socializing and speaking with host nationals. One explanation for the lack of significance in the self-appraisal, use, and regulation of emotion may be students' limited time in the host culture (i.e., 12-15 weeks). Given this relatively brief period, they may have been intimidated by interactions with local nationals and therefore, focused primarily on reading others' emotions. Rather than intentionally assessing, using, or regulating their own emotions to facilitate interaction, they seemed to feel most adjusted when they could better gauge and understand the emotions of their hosts.

Results on the relationship between cross-cultural adjustment and EAO were mixed. Study abroad students with a higher EAO demonstrated stronger interaction adjustment than those with a lower EAO; however, there was no significant difference between the two groups on general adjustment. One explanation for the latter finding may be that housing and logistics for many students are pre-determined in the host culture, thus diminishing their need to take risks or assume responsibility for much of their living conditions. Nevertheless, it seems that an entrepreneurial attitude facilitates the degree of adjustment students feel in interacting with host nationals. Perhaps they are more conscientious and open about socializing and interacting with locals, while having the perceived confidence and ability to handle such interactions successfully.

At least two limitations should be kept in mind regarding the findings in this study. First, because the sample came from a single university, the results may have limited generalizability. Nevertheless, the respondents represented a 
cross-section of disciplines, with a mix of males and females and both experienced and inexperienced international travelers. Second, the lack of more significant results associated with the EAO may be attributed to the abbreviated version of the measure used. Compared to the original version, the current measure did not include cognitive and affective components along with behavioral components. Although the behavioral components alone were reliable, multiple dimensions may have yielded more rigorous results.

Despite these limitations, the findings are suggestive of at least two implications. First, the generally strong relationships found between cultural adjustment and both EI and EAO suggest that these personality characteristics may inform the selection and/or training of prospective study abroad students. Knowing that those students high on EI demonstrate stronger cultural adjustment may lead study abroad selection committees to assess this characteristic among applicants to determine if additional understanding and development of EI is warranted. Similarly, knowing that students with a higher EAO demonstrate stronger interaction adjustment may lead to an assessment and facilitation of this characteristic in applicants as well.

Second, given the dearth of literature on personality characteristics that impact the adjustment and success of study abroad students, future research on personality variables beyond EI and EAO seems warranted. If other key characteristics fostering adjustment can be identified, developed, and exhibited among these students, then their international sojourn can be even more successful, thus having a more profound effect on their personal, academic, and ultimately, professional lives.

\section{Ref ere nces}

Bakalis, Steve, \& Joiner, Therese A. (2004). Participation in tertiary study abroad programs: the role of personality. International Journal of Educational Management, 18(5), 286-291.

Bandura, A. (1986). Social Foundations of Thought and Action. Englewood Cliffs, NJ: Prentice Hall, Inc.

Bhaskar-Shrinivas, Purnima, Harrison, David A., Shaffer, Margaret A., Luk, Dora M. (2005). Input-Based and Time-Based Models of International Adjustment: Meta-Analytic Evidence and Theoretical Extensions. Academy of Management Journal, 48(2), 257-281.

Black, J. Stewart (1990). Locus of Control, Social Support, Stress, and Adjustment in International Transfers. Asia Pacific Journal of Management, 7(1), $1-29$. 
Black, J.S. (1988). Work role transitions: A study of American expatriate managers in Japan. Journal of International Business Studies, 9, 277-294.

Black, J.S., \& Gregersen, H.B. (1991). The other half of the picture: Antecedents of spouse cross-cultural adjustment. Journal of International Business Studies, 22, 461-477.

Black, J.S., Mendenhall, M., \& Oddou, G. (1991). Toward a comprehensive model of international adjustment: An integration of multiple theoretical perspectives. Academy of Management Review, 16, 291-317.

Breckler, Steven J. (1984). Empirical Validation of Affect, Behavior, and Cognition as Distinct Components of Attitude. Journal of Personality and Social Psychology, 47(6), 1191-1205.

Costa, P.T, \& McCrae, R.R. (1992). Four ways five factors are basic. Personality and Individual Differences, 13, 653-665.

Dwyer, Mary M., \& Peters, Courtney K. (2004). The Benefits of Study Abroad: New Study Confirms Significant Gains. Transitions Abroad, 37(5), 56-58.

Gabel, Racheli Shmueli, Dolan, Shimon L., \& Cerdin, Jean Luc (2005). Emotional intelligence as predictor of cultural adjustment for success in global assignments. Career Development International, 10(5), 375-395.

Harrison, J. Kline (2006). The Relationship between International Study Tour Effects and the Personality Variables of Self-Monitoring and Core SelfEvaluations. Frontiers: The Interdisciplinary Journal of Study Abroad.

Harrison, J. Kline, Chadwick, Margaret, \& Scales, Maria (1996). The Relationship between Cross-Cultural Adjustment and the Personality Variables of Self-Efficacy and Self-Monitoring. International Journal of Intercultural Relations, 20(2), 167-188.

Huang, Tsai-Jung, Chi, Shu-Cheng, \& Lawler, John J. (2005). The relationship between expatriates' personality traits and their adjustment to international assignments. International Journal of Human Resource Management, 16(9), 1656-1670.

Huefner, Jonathan C., \& Hunt, H. Keith (1994). Broadening the Concept of Entrepreneurship: Comparing Business and Consumer Entrepreneurs. Entrepreneurship Theory and Practice, Spring, 61-75.

Illieva, Janet, Baron, Steve, \& Healey, Nigel M. (2002). Online surveys in marketing research: Pros and Cons. International Journal of Market Research, July, 361-377.

Jassawalla, Avan, Truglia, Ciara, \& Garvey, Jennifer (2004). Cross-cultural conflict and expatriate manager adjustment: An exploratory study. Management Decision, 42(7), 837-849. 
Kothandapani, Virupaksha (1971). Validation of Feeling, Belief, and Intention to act as Three Components of Attitude and their Contribution to Prediction of Contraceptive Behavior. Journal of Personality and Social Psychology, 19(3), 321-333.

Mayer, JD, \& Salovey P. (1993). The Intelligence of Emotional Intelligence. Intelligence, 17(4), 433-442.

McCline, Richard L., Bhat, Subodh, \& Baj, Pam (2000). Opportunity Recognition: An Exploratory Investigation of a Component of the Entrepreneurial Process in the Context of the Health Care Industry. Entrepreneurship: Theory \& Practice, 25(2), 81-94.

McShane, Steven L., \& Von Glinow, Mary Ann (2005). Organizational Behavior. New York: McGraw-Hill Irwin.

Nicholson, N. (1984). A theory of work role transitions. Administrative Science Quarterly, 29, 172-191.

Ornstein, Suzyn, \& Nelson, Teresa (2006). Incorporating emotional intelligence competency building into the preparation and delivery of international travel courses. Innovations in Education and Teaching International, 43(1), 41-55.

Rahim, M. Afzalur, \& Psenicka, Clement (2002). A Model of Emotional Intelligence and Conflict Management Strategies: A Study in Seven Countries. The International Journal of Organizational Analysis, 10(4), 302-326.

Robie, Chet, \& Ryan, Ann Marie (1996). Structural Equivalence of a Measure of Cross-Cultural Adjustment. Educational and Psychological Measurement, 56(3), 514-521.

Robinson, Peter B., Stimpson, David V., Huefner, Jonathan C., \& Hunt, H. Keith (1991). An Attitude Approach to the Prediction of Entrepreneurship. Entrepreneurship Theory and Practice, Summer, 13-31.

Salovey, P., \& Mayer, J.D. (1990). Emotional Intelligence. Imagination, Cognition, and Personality, 9, 185-211.

Schroth, Marvin L., \& McCormick, William A. (2000). Sensation Seeking and Need for Achievement among Study-Abroad Students. The Journal of Social Psychology, 140(4), 533-535.

Shaffer, Margaret A., Harrison, David A., \& Gilley, K. Matthew (1999). Dimensions, Determinants, and Differences in the Expatriate Adjustment Process. Journal of International Business Studies, 30(3), 557-581.

Shaffer, Margaret A., Harrison, David A., Gregersen, Hal, Black, J. Stewart, \& Ferzandi, Lori A. (2006). You Can Take It With You: Individual Differences and Expatriate Effectiveness. Journal of Applied Psychology, 91(1), 109-125. 
Frontiers: The Interdisciplinary Journal of Study Abroad

U.S. Study Abroad Increases by 9.6\%, Continues Record Growth. (2005, November 14). IIE Network.

van Wyk, R., and A.B. Boshoff (2004). Entrepreneurial Attitudes: A distinction between two professional groups. South African Journal of Business Management, 35(2), 33-38.

Vande Berg, Michael (2003). The Case for Assessing Educational Outcomes in Study Abroad. Advances in International Marketing, 13, 23-36.

Wong, Chi-Sum, \& Law, Kenneth S. (2002). The effects of leader and follower emotional intelligence on performance and attitude: An exploratory study. The Leadership Quarterly, 13, 243-274. 


\section{Appendix 1}

\section{Cross-cultural Adjustment Measure}

Please answer the following questions about how unadjusted or adjusted you were to the following during your study abroad experience:

\begin{tabular}{|l|l|l|l|l|l|l|l|}
\hline \multicolumn{2}{|c|}{$\begin{array}{c}\text { Almost no } \\
\text { adjustment }\end{array}$} & $\mathbf{1}$ & $\mathbf{2}$ & $\mathbf{3}$ & $\mathbf{4}$ & $\mathbf{5}$ & $\begin{array}{c}\text { Tremendous } \\
\text { adjustment }\end{array}$ \\
\hline 1. & Living conditions (in general) \\
\hline 2. & Housing conditions \\
\hline 3. & Food \\
\hline 4. & Shopping \\
\hline 5. & Cost of living \\
\hline 6. & Entertainment/recreation facilities \\
\hline 7. & Health care facilities \\
\hline 8. & Socializing with host nationals (i.e., local citizens) \\
\hline 9. & $\begin{array}{l}\text { Interacting with host nationals (i.e., local citizens) on a } \\
\text { day-to-day basis }\end{array}$ \\
\hline
\end{tabular}




\section{Appendix 2}

\section{Emotional Intelligence Measure}

\begin{tabular}{|c|c|c|c|c|c|c|c|}
\hline Scale: & $\begin{array}{l}\text { Strongly } \\
\text { disagree }\end{array}$ & 1 & 2 & 3 & 4 & 5 & Strongly agree \\
\hline 1. & \multicolumn{7}{|c|}{$\begin{array}{l}\text { I have a good sense of why I have certain feelings most of the } \\
\text { time. }\end{array}$} \\
\hline 2. & \multicolumn{7}{|c|}{ I have good understanding of my own emotions. } \\
\hline 3. & \multicolumn{7}{|c|}{ I really understand what I feel. } \\
\hline 4. & \multicolumn{7}{|c|}{ I always know whether or not I am happy. } \\
\hline 5. & \multicolumn{7}{|c|}{ I always know my friends' emotions from their behavior. } \\
\hline 6. & \multicolumn{7}{|c|}{ I am a good observer of others' emotions. } \\
\hline 7. & \multicolumn{7}{|c|}{ I am sensitive to the feelings and emotions of others. } \\
\hline 8. & \multicolumn{7}{|c|}{$\begin{array}{l}\text { I have good understanding of the emotions of people around } \\
\text { me. }\end{array}$} \\
\hline 9. & \multicolumn{7}{|c|}{$\begin{array}{l}\text { I always set goals for myself and then try my best to achieve } \\
\text { them. }\end{array}$} \\
\hline 10. & \multicolumn{7}{|c|}{ I always tell myself I am a competent person. } \\
\hline 11. & \multicolumn{7}{|c|}{ I am a self-motivated person. } \\
\hline 12. & \multicolumn{7}{|c|}{ I would always encourage myself to try my best. } \\
\hline 13. & \multicolumn{7}{|c|}{ I am able to control my temper and handle difficulties rationally. } \\
\hline 14. & \multicolumn{7}{|c|}{ I am quite capable of controlling my own emotions. } \\
\hline 15. & \multicolumn{7}{|c|}{ I can always calm down quickly when I am very angry. } \\
\hline 16. & \multicolumn{7}{|c|}{ I have good control of my own emotions. } \\
\hline
\end{tabular}




\section{Appendix 3 \\ Entrepreneurial Attitude Orientation Measure}

\begin{tabular}{|c|c|c|c|c|c|}
\hline \multicolumn{3}{|l|}{$\begin{array}{l}\text { Below are several more statements about you with which you may agree or } \\
\text { disagree. }\end{array}$} \\
\hline Using the scale below, indicate your (dis)agreement with each item.
\end{tabular}

[continued on next page] 


\begin{tabular}{|c|l|}
\cline { 2 - 3 } 23. & $\begin{array}{l}\text { My knack for dealing with people has enabled me to create } \\
\text { many new opportunities. }\end{array}$ \\
\hline 24. & $\begin{array}{l}\text { I always try to make friends with people who may be useful in } \\
\text { my personal success. }\end{array}$ \\
\hline 25. & $\begin{array}{l}\text { I usually seek out colleagues who are excited about exploring } \\
\text { new ways of doing things. }\end{array}$ \\
\hline${ }^{*} 26$. & $\begin{array}{l}\text { I always follow accepted social or professional practices in } \\
\text { the dealings I have with others. }\end{array}$ \\
\hline${ }^{*} 27$. & I rarely question the value of established procedures. \\
\hline
\end{tabular}

